\title{
Advancing Scholarly Leadership by Forming a Community of Scholars
}

\author{
Dr. Janice (Jan) Cardwell \\ Campus Vice President/Director \\ University of Phoenix - Detroit \\ Dr. Bonnie Ellis \\ Director of Academic Affairs \\ University of Phoenix - Detroit \\ Dr. Yvonne Phelps \\ Vice President of Academic Affairs for Campus Services \\ University of Phoenix
}

\begin{abstract}
Campus leadership at a satellite campus of a large national university took a research approach to solve the workplace problem of increased scholarship requirements for practitioner faculty. The Community of Scholars Action Research Project was developed as a faculty engagement and professional development initiative. The goals and objectives for the action research project were to engage practitioner faculty in research and scholarship, to provide faculty development opportunities, to raise the academic profile of practitioner faculty and to identify potential impact on student outcomes. Through the processes of research, exploration, and application of leadership theoretical frameworks, the concept of a potentially new leadership profile, scholarly leader, emerged.
\end{abstract}

\section{Introduction}

This research defines practitioner faculty as an industry professional with the appropriate credentials who is also teaching in higher education. With dual responsibilities, practitioner faculty retain a career in industry while preparing and facilitating college courses (Cardwell, Ellis, \& Phelps, 2016). These professionals integrate their industry expertise, current industry practices, and industry information, with course content, to prepare learners for post degree career opportunities. The practitioner faculty model works well for three specific reasons. (1) For students, the industry practitioner can relate course content and theory to current industry issues, problems or experiences (Cardwell, Ellis, \& Phelps, 2016). Adult students receive an interactive and dynamic experience for learning that transfers into the workplace. (2) The industry practitioner continues his or her professional career, in industry, while creating an academic career profile in higher education (Reybold, 2008). (3) University instructional human resource needs are satisfied with qualified industry experts to prepare students for career mobility (Cardwell, Ellis, Phelps, 2016). 


\section{Problem}

The benefits of the practitioner faculty model fall short in one specific area, practitioner faculty engaging in research and scholarship. In 2013 the Higher Learning Commission (HLC) included "faculty pursuit of intellectual inquiry and evidence of faculty scholarship as a criterion for accreditation" (HLC, 2013 Criterion 3.B.5). The problem is that while the practitioner brings industry knowledge, current practices, and industry information into the learning environment there is a skill gap with practitioner faculty engaging in research and scholarship (Bartunek \& Rymes, 2014). This skill gap exists while concurrently advancements in learning management systems, social media, technologies, and other societal changes are impacting and influencing how learning takes place (Johnson, Adams Becker, Estrada, \& Freeman, 2015). Faced with these new requirements for faculty scholarship, a large national and non-traditional university identified two ways to address their faculty skill gap challenge. First, the university updated credential requirements for faculty teaching at the master's level and above to ensure that faculty members had research experience. From there guidelines could be put in place requiring research or scholarship as a requirement for continued employment. The second, and most significant problem was how to increase engagement and develop the skills for research and scholarship with faculty already hired and teaching classes to align with the new HLC guidelines. To address this problem, administrative leaders at a satellite campus of the university approached the problem as a research project.

\section{Community of Scholars Action Research Project}

Purpose. The purpose of this study was because new guidelines for HLC accreditation required practitioner faculty to engage in intellectual inquiry and shift to new academic personas; which required a faculty development initiative. Recognizing that employee engagement and staff development are leadership responsibilities, the campus leaders needed a strategy to increase faculty engagement with research and scholarship. They started with an analysis of the obstacles, which included: experience gaps, skill gaps, and motivation gaps for research and scholarships. The experience gap was no recent research experience. Many instructors had been teaching for ten or more years and there had been no requirement to engage in research or scholarship by the University, so their skills had diminished. The skill gap was simply lack of exposure or learning. There was hesitancy, by faculty members, to admit knowledge limitations on how to write or conduct a research study. Motivation gaps were communicated as lack of interest in research and scholarship activities or not having the time to start or complete a research study. This was due to, job, family, or personal business responsibilities. Faculty needed to learn research techniques while still focusing on students, then conduct research, and actively create academic networks (Raina \& Khatri, 2015). The reality faced by the campus leadership is that adding research or scholarship requirements, represented more work for practitioner faculty with no additional compensation, which created a potential risk of losing experienced faculty members.

Study Population. The population for this study was practitioner faculty in Southeast Michigan. These faculty were hired because of their credentials to have five years of industry experience and master's level or above education. They are officially called associate faculty. These faculty teach online, in the classroom, or both. There are approximately 200+ active faculty at the time this study began, all were invited to participate. 
Theoretical Foundations. The Community of Scholars Action Research Project was launched fall 2016. Boyer's (1990) Scholarship of Discovery (Figure 1) provided the overarching theoretical foundation for the action research project.

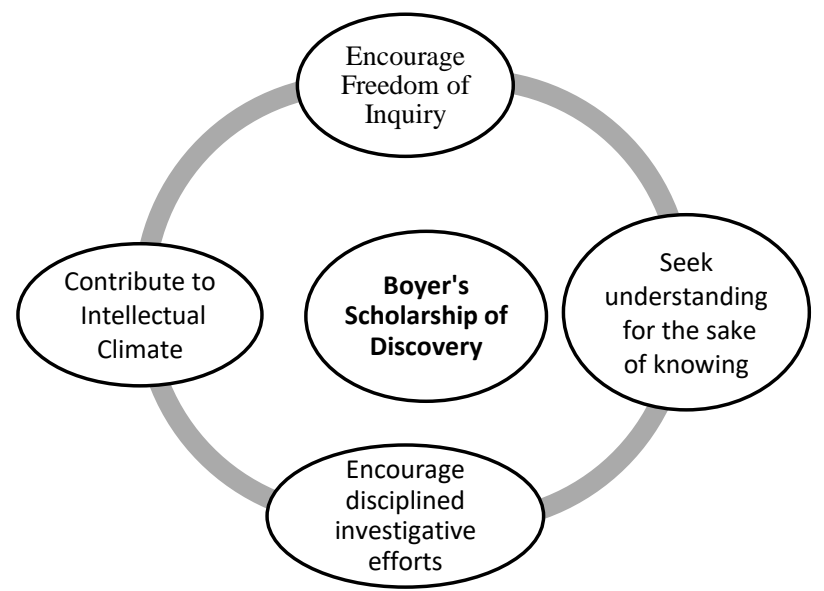

Figure 1. Adapted from Boyer, E. (1990). Scholarship Reconsidered: Priorities of the Professoriate. San Francisco: Jossey-Bass. The Carnegie Foundation for the Advancement of Teaching.

As the project developed, the researchers conceptualized the emergence of a leadership profile they termed scholarly leadership. Drawing from behaviors found in the servant (Greenleaf, 1970), situational (Hersey \& Blanchard, 1969), and transformational (Burns, 1978 \& Bass, 1985) theories on leadership, the researchers drew components from each theory (Figure 2) to formulate a concept to explain the leadership behaviors they drew upon during this study. According to Ravitch and Riggan (2012), a conceptual framework provides an opportunity for researchers to offer discovery of potential frameworks that emerged from the research.

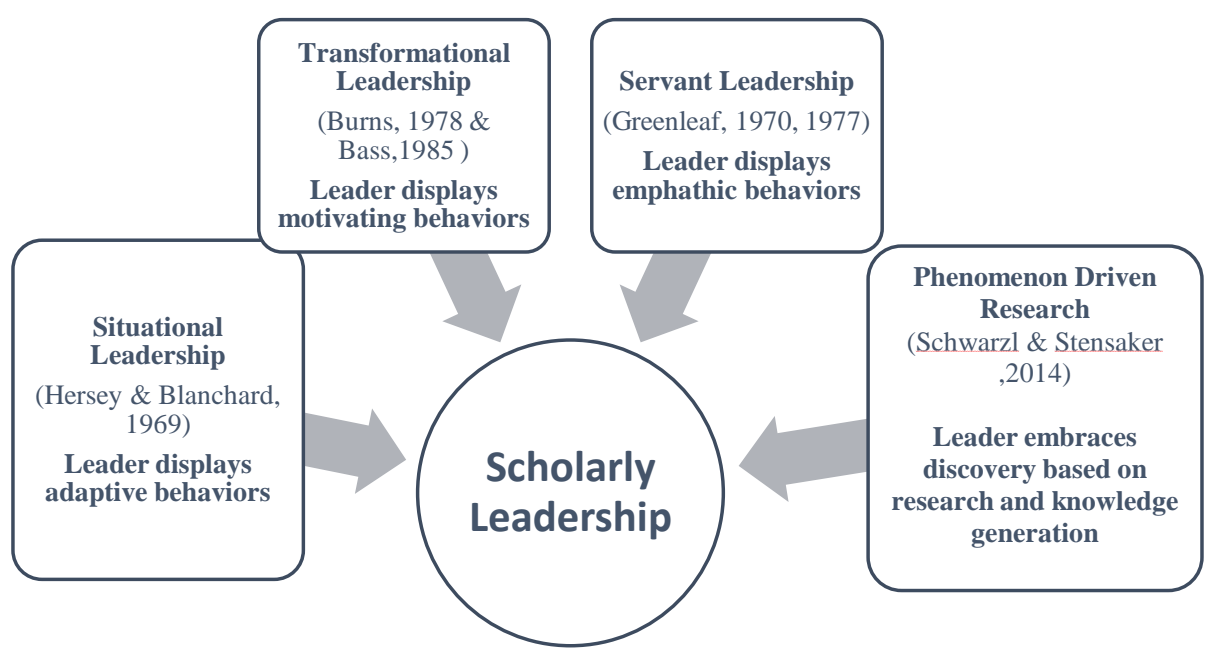

Figure 2. Conceptual framework for Scholarly Leadership 
Goals and Objectives. Campus leadership had four primary goals for the Community of Scholars Action Research Project: faculty development, faculty engagement, student outcomes, and faculty professional identity. The first goal was to inspire faculty engagement. Immediately, when communicated, the term Community of Scholars introduced a new membership identity for practitioner faculty. As explained by Boyer (1990) the scholarship of discovery is driven by the passion and excitement inspired by the process. Informal and formal gap analysis, conducted by the leaders, revealed motivational constraints among practitioner faculty to engage in research or to join the community of scholars. Faculty communicated concerns about time, personal research interests, concerns about sharing research ideas and more. The campus leaders hypothesized that they could ignite passion for research (Boyer, 1990) by uncovering and promoting individual's research interests. By giving community member a platform to share research interests and ideas they encouraged freedom of inquiry and understanding for the sake of knowing. Researchers paid close attention to their ideas, complimenting and encouraging individual practitioner faculty's motivations for research or scholarship. These transformative leadership behaviors (Burns 1978 \& Bass, 1985) were specifically used to motivate and inspire practitioners to join the Community of Scholars.

The second goal was to provide faculty with developmental training. The gap analysis in the first cycle of the action research revealed the need for training on research methodologies, approval processes, analysis processes, and funding opportunities. The leaders conceptualized that disciplined investigative efforts could be accomplished if they addressed the identified skill gaps. While planning to create a climate of intellectual inquiry the leaders needed to be empathetic and understanding, not just for the identified skill gaps but also for the hesitancies to communicate that skill gaps existed. They found that many practitioner faculty had been teaching for more than ten years and admitting skill gaps was not a comfortable space for them. This servant leadership behavior (Greenleaf, 1970) helped to create an environment of acceptance and respect in the community.

The third goal was to help faculty to understand why research and scholarship were important to their academic careers. Recognizing the experiential gaps as well as the time gaps for research and scholarship required a situational approach (Hersey \& Blanchard, 1969) Different faculty members had different needs from the community. This required the leaders' behaviors and communications styles to adapt to each individual's situation. For example, while forming the community, the leaders needed to be directive. A directive approach was needed because action research was new to faculty members. The leaders had to direct and guide understanding of the intent and process for action research. Other situations required the leaders to be supportive or to coach. Leaders found that there was no one approach that could be applied in the process, which required their adaptive behaviors.

Specific outcome goals for Community of Scholars membership were to: (1) improve skill gaps with training; (2) encourage collaboration on research projects; (3) reduce time restraints and/or hesitancies to get started with and complete research projects; and (4) give community members a platform to discuss or present their projects. The researchers found the scholarly leader approach to this workplace problem empowering; adapting a discovery approach to the workplace problem allowed everyone, including the leaders, to be learning. 
The fourth and overarching objective of the action research initiative was to promote a culture of scholarship to improve student outcomes. The intentionality was to develop leaders in research and scholarship and to develop faculty role models for scholarship. Potential student outcomes included engaging/improving student's intellectual inquiry (learning), improving student retention (excitement about learning), and encouraging student scholarship (interest in research and scholarship beyond coursework). Table 1 provides a comprehensive list of the goals and objectives of the action research.

Table 1. Community of Scholars Research Project Goals and Objectives
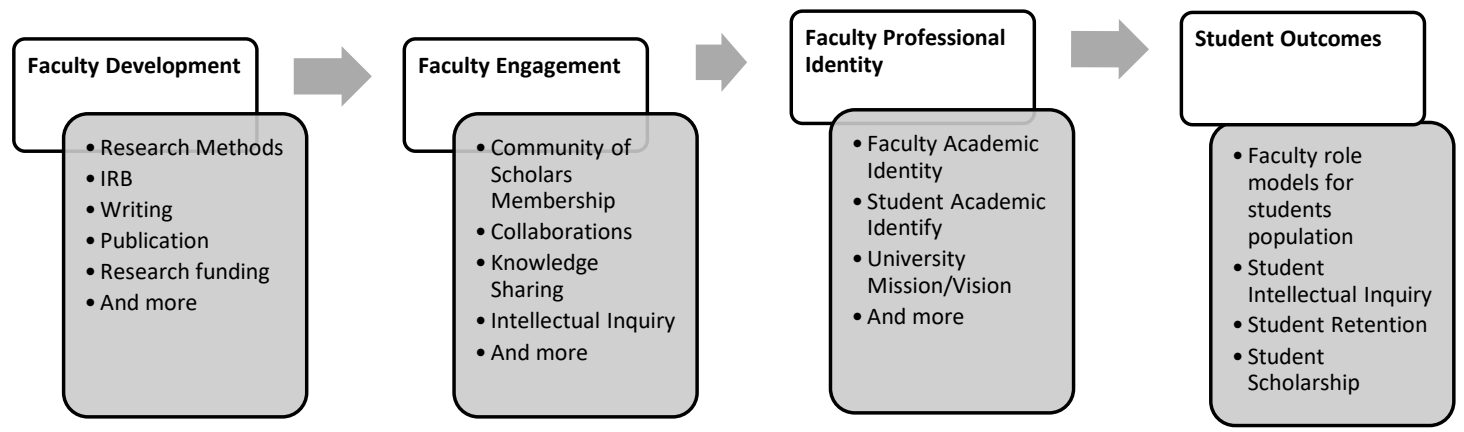

\section{Questions and Content}

1. What are the challenges, processes, and opportunities to form a Community of Scholars among practitioner faculty? This question was to uncover leadership opportunities and skills that can be developed by everyone involved in the Community of Scholars Action Research project.

2. How does the formation of a Community of Scholars impact faculty engagement in research and scholarship in adult learning environments? This question was to uncover processes that work well or do not work well with faculty from diverse education and industry backgrounds.

3. How can the formation of a Community of Scholars contribute to student outcomes? This question is designed to begin and maintain dialogue with faculty on how their scholarship impacts students' intellectual inquiry.

\section{Literature Review}

Practitioner faculty had been used as a hiring model for over four decades at the university where this study took place. Despite this forty-year faculty hiring practice, there is a paucity of research on practitioner faculty to be found in published literature. A key challenge uncovered, during the search for relevant literature, was that the term practitioner is used in a variety of contexts across many disciplines. Search terms for this study included: practitioner faculty, faculty engagement, faculty development, faculty research, leadership and scholarly leadership. 
Practitioner Faculty and Research. Bartunek and Rynes (2014) offered a discourse on "the paradoxes of academic- practitioners and academic-academics." They concluded that tensions or differences, around research, existed between the "academic-practitioner and the academic-academic" (p. 1197). Specifically, the practitioner approached research from the business timeline perspective while the academic-academic had no set timelines for research to be completed. The differing timeline was something to be mindful of when attempting to engage practitioner faculty in research and scholarship for this study. Finding time to start or complete a research study is a real concern for practitioners coming from business or non-educational environments.

Reybold (2008), conducted a study to explore how adult education practitioners balance their professional identities. Drawing from interviews with eight practitioners teaching in adult education environments he concluded: "there existed a balancing act and continuous reframing of professional identity" for practitioners (p. 145). Reybold's study also uncovered some of the challenges that practitioners have with being considered an academic, which included concerns about finding time for research or finding time to write for publication or other scholarly activities.

The 2015 Horizon Report cites the European Commission's Modernizing Universities agenda that recommends reforms in higher education intended to encourage open research, develop stronger businesses partnerships, and reexamine faculty qualifications (Johnson, et al, 2015). Missing from this list of reforms was how to stimulate faculty research in non-traditional learning environments.

The Higher Learning Commission's 2013 Accreditation Criterion emphasized the need for intellectual inquiry. Specifically, criterion 3.B.5 states "faculty and students contribute to scholarship, creative work, and the discovery of knowledge to the extent appropriate to their programs and the institution's mission." In the competitive landscape of higher education, learning institutions must be in alignment with accreditation criteria despite prior faculty hiring models or non-traditional learning environments.

Boyer's Scholarship of Discovery provides a theoretical foundation to encourage faculty research. As explained by Boyer (1990) the scholarship of discovery encourages "freedom of inquiry; understanding for the sake of knowing; and disciplined investigative efforts that contribute to the intellectual climate" of the education environment (p.17). The challenge with the application of Boyer's constructs, for this study, was the skill gap on how to conduct research and the time constraints that existed with practitioner faculty.

Raina and Khatri's (2015) exploratory study examined faculty engagement practices across institutions of higher learning. Although the focus of the study was to compare Indian and non-Indian practices for faculty engagement, they also uncovered and cataloged best practices and challenges that many higher education institutions face with faculty engagement. They concluded that there had been a transformation of the role of faculty in higher education from traditional teaching. The new paradigm requires faculty members to "acquire new forms, learn new techniques, focus on students, conduct research, and actively create competitive networks" (p. 301). The literature they uncovered reflects that faculty leave teaching jobs because of these 
new demands, which often come with no financial or opportunity benefits. The challenge for education leaders is to encourage faculty engagement despite the negative perceptions

Leadership and Scholarly Leadership. Northouse (2007) defined leadership as "a process where an individual is able to influence a group of individuals to achieve a certain goal" (p. 3). This definition explains the outcome of leadership, it confirms why leadership is important and what the leader should be doing; however, it does not explain how the leader is to engage and develop human resources to achieve the goal. Perruci (2011), defined leadership "as a process by which leaders and followers develop a relationship and work together toward goals within an environmental context shaped by cultural values and norms" (p. 84). This definition clarifies the importance of environmental and cultural situations; however, what is also missing is how the leader can get it done. Missing from both definitions of leadership was how the leader is to engage and develop individuals in the workplace to work toward a goal. This study was designed to engage and develop practitioner faculty in disciplines of research and scholarship; therefore, we had to draw on theoretical concepts of leadership that explain how leaders get things done.

There are many theories to explain leadership behaviors and many theories that can be used when designing an employee engagement or professional development initiative. The servant leader (Greenleaf, 1970), the situational leader (Hersey and Blanchard, 1969), and the transformational leader (Burns, 1978) are just a few of the accepted leadership theories in modern society. Some leaders position themselves as the servant leaders to engage their human resources (Greenleaf, 1970, 1977). This servitude approach is not to diminish the leader's power or authority; on the contrary, the servant leadership approach is used to empathize and take care of their followers as a strategy for engagement (Greenleaf, 1970, 1977). This Community of Scholars research involved engaging practitioner faculty who had been teaching in higher education, some for ten or more years. There was hesitancy by faculty members to admit their knowledge limitations about how to conduct a research study. The servitude approach, applied in this study, was to emphasize understanding for the knowledge gaps and to recognize the associated emotions behind faculty hesitations to engage in the project.

Some leaders lean more towards a situational leadership approach. Hersey and Blanchard (1969) theorized that to increase employee engagement and outcomes requires the leader to adapt behaviors and communications styles to the situation. Some situations require the leader to be directive. Other situations require the leader to be supportive. Situational leadership is based on assumptions that employees have a variety of skills and motivations; therefore, leadership is not a broad-brush approach (Northouse, 2007). The situational approach applied in this research required delegating, supporting, coaching, and directing (Blanchard, 1985) based on the practitioner faculty member's personal situations surrounding research and scholarship. The transformative leader creates a vision then inspires others to engage with and commit to completion of the goal or desired outcomes, conceptually raising levels of motivation to complete the goal (Burns, 1978). A key behavior of the transformative leader is the attention paid to the personal motivations of the individual. Bass (1985) expanded the dialogue on transformative leadership by describing behavioral factors exhibited by transformational leaders as idealized charismatic influence, inspiring and motivating, intellectually stimulating, and considerate of individualization. The transformative approach applied in this study involved 
finding intellectually stimulating ways to influence and motivate faculty to start research projects with consideration for how this new job requirement would fit in with their other jobs and teaching responsibilities. Schwarzl and Stensaker (2014), argued that change research has become so dependent on advancing existing theories of practice that it has "become a figurative straightjacket, hampering real progress in knowledge and encouraging work on popular topics that fall within the realm of the most well-known already existing theories" (p. 479). They proposed phenomenon driven research as an approach to research that pushes beyond known management theories to create new knowledge and new approaches to organizational change. This approach to management theory offers potential for new leadership concepts to be explored by encouraging leaders to look beyond conventional or established theories.

\section{Research Design}

While considering the methodology for this study, the researchers identified that the research questions were behavioral leadership concerns, so they consider a mixed design approach to the research. Elliot's Model for Action Research (2010) was the overarching strategy to create faculty engagement and the focus for this project. Yin's (1994) Case Study approach could be a follow-up iteration to document the individual faculty and leader experiences, and Grounded Theory (Corbin and Strauss, 1990) for future exploration of any theoretical discoveries. The leader's intellectual inquiry was what can we learn from this experience and how can we share this with other leaders facing a similar workplace challenge?

Action Research. Elliot's Model for Action Research (2010) is the overarching research design because of the participatory aspects of the model. The goal was to encourage faculty to feel empowered, to have a voice, and to engage with the Community of Scholars. Participation is a key component of action research, which includes the following:

- Research in action, rather than research about action: Using a scientific approach to study the resolution of important organizational issues along with those who experience the issues directly.

- Participative and democratic: Members of the system being studied participate in the cyclical process.

- Research with people rather than on people.

- Concurrent with action: The goal is to make the action more effective while building up a body of scientific knowledge.

- Sequential problem solving: Iterative cycles of gathering data, feeding it back to those concerned, analyzing the data, planning action, taking-action and evaluating leading to further data gathering, and so on. Coghlan, (2004)

Elliot proposed that action research should allow for original ideas to evolve as the research project unfolds (2010). Drawing from Elliot's model the cycles of discovery, for this study, provided opportunities for data collection, reflections, and observations that drove the action research agendas and activities. 

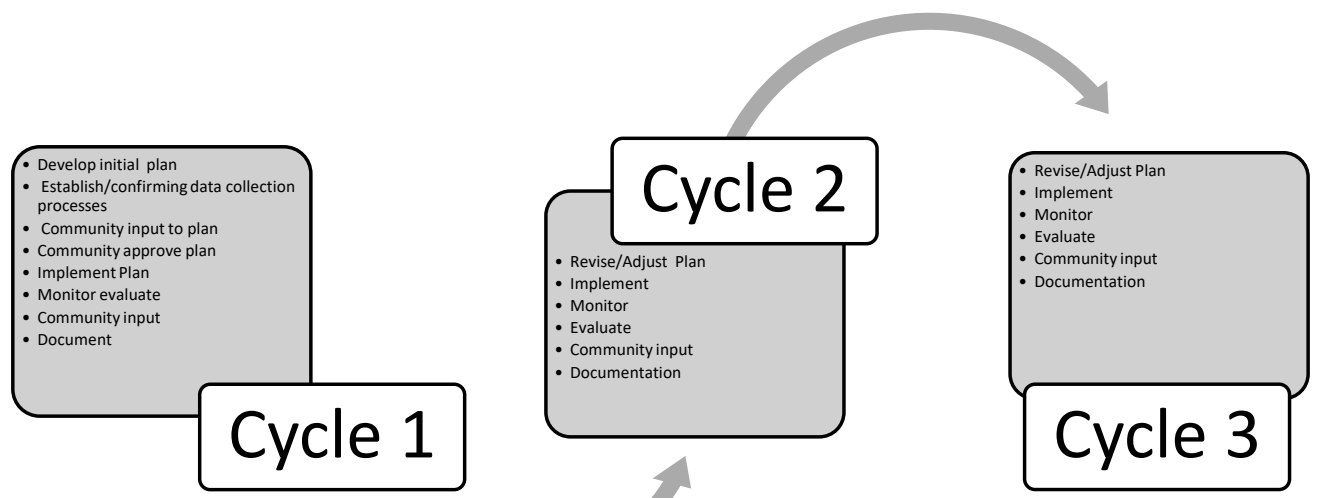

Figure 3. Action Research Cycles of Discovery.

Adapted from Elliott (2010). Building social capital for educational action research: the contribution of Bridget Somekh. Educational Action Research. (18) 1. Pp. 19-28. DOI: 10.1080/09650790903484509

Cycle 1: Forming the Community of Scholars (COS). An email was sent to over 200 active faculty inviting them to join the Community of Scholars and attend an orientation in November 2016. Twenty-two faculty members attended this initial gathering, completed consent forms and joined the community. The orientation included an overview of the community of scholar's goals and objectives, a presentation on action research, and the goals for the research study. This first data collection point was also to confirm skill gaps that had been communicated informally. Training requests included tutelage on conducting a literature review, research methodologies, training on Institutional Research Board (IRB) submissions and more. The community wanted workshops on writing for publications or presentations and insight regarding research funding. The training needs information allowed researchers to look for opportunities or events that would provide practitioner faculty with exposure, training, or additional scholarship opportunities. Table 2 provides a list of the communicated training interests.

Table 2. Faculty Training Interests Feedback

$\begin{array}{ll}\text { Writing a Research Prospectus } & \text { Writing for publication or presentation } \\ \text { Writing a Literature Review } & \text { The IRB process } \\ \text { Finding Funding for Research } & \text { Quantitative Research Methodologies } \\ \text { Data Analysis } & \text { Qualitative Research Methodologies }\end{array}$

In addition to the training needs the researchers asked practitioner faculty to share their individual research goals. Faculty were asked to share their research goals to gain an understanding of what research projects practitioner faculty wanted to pursue. With this 
information, the researchers grouped research interests thematically into research interests' collaboration groups (Table 3). These grouping were to address motivation gaps by encouraging faculty to find research partnerships that could reduce the expressed time or life constraints to conduct research.

\section{Table 3. Research Interests Collaboration Groups}

Research Interest Collaboration Groups

Examining Alternative Technologies for Learning

\# Faculty Members

Exploring Human Health Sociologies

Investigating Learning Behaviors

Examining Business/Workplace Administrations and Business Career Preparations

Exploring Social/Economic Impacts on Learning

Investigating Internal Impacts on Learning and Learning Assessments

Examining and Exploring Cultural Competence in the Workplace for the Purpose of

Data collected during orientation also included observations and self-reflections of the newly identified Community of Scholars. As the community was forming the leaders wanted to identify the pain points faculty would share about the action research. Tables 4 and 5 provide a listing of observation and self-reflections from community members at the orientation meeting.

Table 4. Observations of Community of Scholars

- Hoping there are many hands-on events, so I do not forge the material

- My observations today helped me to clarify the direction of the community of scholars

- Need to set milestones to get us through the process in 12 months

- We need to hold local conference to provide local opportunities to present

- Investment is key and critical to success- which goes beyond the classroom-oriented activities

- External training is needed for personal and professional growth

- The WebEx and other items included in this program are needed for success 
Table 5. Community of Scholars Self-Reflections

- Information is well received

- Concerns about time commitments and possible \$ outlay. Funding

- Length of time, commitment needed

- Space for someone not pursuing a doctorate

- I am not sure how I will be able to connect with the community. It seems like a great idea, but I think we are all at different levels and without mechanisms for me to stay connected to the group in between meetings

- Looking forward to watching the process move forward

The observations and self-reflections were necessary for leaders to determine the impact of this leadership initiative on COS members and to develop plans for the next cycle of the research process.

Cycle 2: Evolving the Community of Scholars (COS). The second participatory event was in February 2017. The Knowledge without Boundaries Academy (KWBA) event was hosted by the University Research Centers. This event provided a unique opportunity for the COS. Practitioner faculty were able to discuss research project needs, develop research ideas, share challenges and talk about limitations with university research experts. The event included a panel of industry experts who shared their organizational research needs. The panel was to help the COS members with ideas for research projects. Breakout sessions included: developing a research idea or research questions, writing research prospectus, quantitative and qualitative research methodologies and designs, research approval processes, and more. COS members attended breakout sessions based on the status of individual research projects. At the end of this event COS members were asked to complete a questionnaire about their level of comfort for research. What was learned is that $63 \%$ of the respondents said they knew a few things about research. Considering there was a low response to the questionnaire (11 responders) this still represented about $50 \%$ of community members. The pie chart in figure four summarizes the responses to the question.

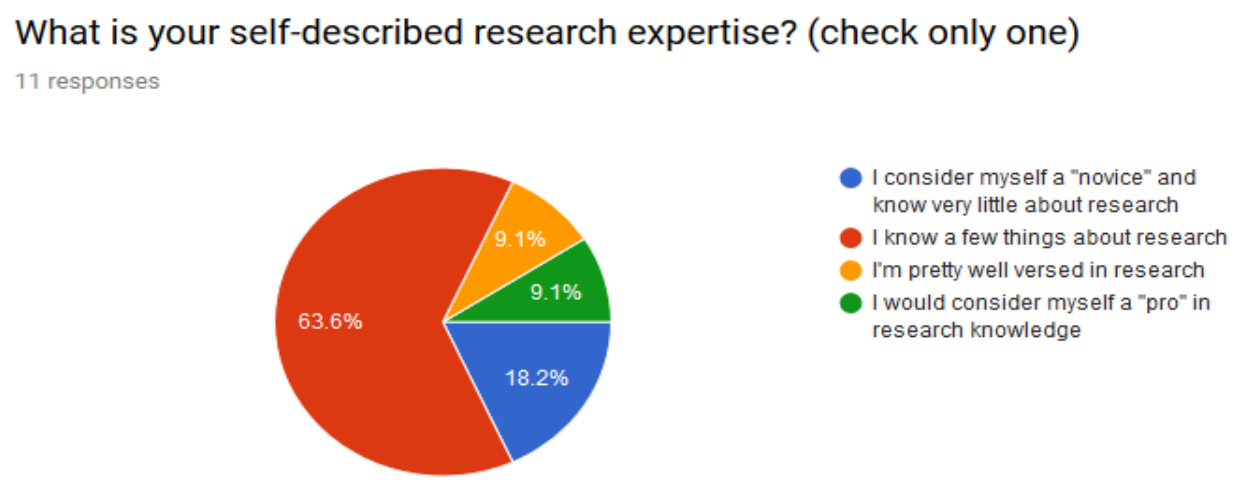

Figure 4. Cycle 2 Knowledge without Boundaries Academy questionnaire feedback

The researchers also used the event to observe COS members scholarship interactions. Table 6 provides the researchers' observations. 
Table 6. Observations of COS members during KWBA event

- Identification with the Community of Scholars. Community members mentioned belonging to the COS. One member wanted to be sure that we did not lose the COS when discussing the KWBA.

- $\quad$ Research Moving Forward. COS members were moving their research forward. Individuals gave more thought and effort to scholarship/research. They have better-developed research ideas and were interested in taking the next steps in the process. We continue to have examples of individuals who have made presentations, are scheduled to make presentations, have published or are in the process of publishing articles.

- Increase in Participation. More individuals attended the KWBA than attended the prior research event the prior year. The new format stimulated research ideas (panel) and allowed for participation in the research process at the level each person was at when they attended.

- Increase in Collaboration. Individuals were reaching out to others with similar interests.

- Increase in Understanding. Attendees had an increased comfort level when discussing scholarship/research. They seemed to embrace the discussion and were more engaged in understanding the process.

- $\quad$ Expressed Satisfaction and Progress. Attendees expressed satisfaction with the event and discussed progress that had been made in furthering their research.

- High Level of Support. Attendees were surrounded with a high level of support from the University School of Advanced Studies staff and research fellows. Support was commented on by COS attendees.

The third participatory event April 2017 was a faculty meeting. The Director of Academic Affairs, designed the faculty meeting as a mini scholarship conference. She sent out a call for presenters and put a process in place for responses. Eleven members of the COS volunteered to provide an overview of their research projects to an audience of peer faculty members. COS members provided updates on where they were in the research process for their projects. The COS presentations provided a unique opportunity for a scholarship activity. Table 7 lists the titles of research presentations at the faculty meeting. 


\section{Table 7. Research Presentations}

Students and Teachers Against Violence \& Crime: A Lesson in Servant Leadership

Denied Access: Fathers are Parents, Too

Self-directed Learning Readiness in Accelerated, Blended Programs

How to Improve the Retention Rate of First Generation/Year Students

Experiential Learning from the Classroom to the Boardroom

The Impact of Nutrition Education on Dietary Habits \& Health Status

Is Higher Education a Business

Cognitive Bias in Research: Issues and Insights

Stereotypes and Barriers: Effects On C-Suite Career Progression of African American Females: A Narrative Inquiry

Student End of Course Survey Research Project

A second questionnaire was distributed to COS attendees during this event to gauge again the level of comfort for research using the same questions from the February event. There was a shift in the self-described research expertise from February to April 2017. Again, the response was low (16 responders); however, more provided feedback than the previous data point.

\section{What is your self-described research expertise?}

16 responses

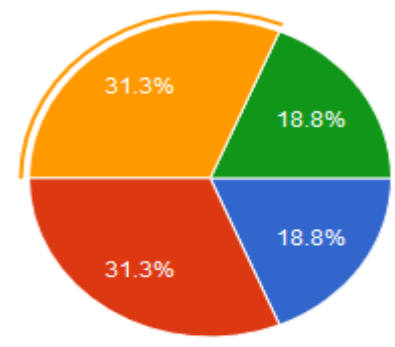

I consider myself a "novice" and know very little about research I know a few things about research

I'm pretty well versed in research

I would consider myself a "pro" in research knowledge

Figure 5. Cycle 2 General Faculty Meeting questionnaire feedback

During cycle 2 of the project, the researchers realized that evolution of the COS required a communication process and that community members would need to take a leadership role for sustainability. The University Research Center provided the campus with a micro site for campus level scholarship. This micro site was a functional platform for COS members' research or scholarship activities to be showcased and for members to communicate or find communications on research. Two positions were established to support the Community of Scholars. The first was 
a COS Communications Liaison. This position was put in place to manage the campus micro site. On the micro site, faculty research projects could be showcased, and faculty could blog as well as engage in forums. The second support position was the COS Research Liaison. This was a faculty member with extensive research experience to provide support with research planning and data collection.

Cycle 3: Sustaining the Community of Scholars (COS). The fourth participatory event was a COS meeting held in June 2017. The community members used a round table concept to share their research project ideas and to provide an update on where they were in the research process. This training event included a presentation from a doctoral alumnus who had been challenged during his IRB process, a presentation on the campus community research site, and a presentation on how to get published and how to join virtual research communities. The final presentation was to provide the community with an update on their action research feedback. Table 8 provides a summary of the COS research projects, methodology, and status.

Table 8. Summary of COS Projects

\begin{tabular}{lll} 
Project name & Methodology & Status \\
\hline Using Virtual \Technology in Learning Process & Quantitative & Lit. Review \\
Is Higher Education a Business & Quantitative & Writing for publication \\
Self-Directed Learning Readiness in Accelerated/ Blended Environments & Quantitative & IRB Approval \\
Student Engagement for Virtual High School Learning & Qualitative & Writing for publication \\
Effect of Faculty Interactions on Student Evaluations & Quantitative & Writing prospectus \\
Effect of Lack of Fathers on African American Males & Quantitative & Writing prospectus \\
A Village Approach to Writing & Case Study & Writing prospectus \\
Stereotypes and Barriers Affecting African American Females C-Suite Progression & Narrative & IRB Approval \\
Recognition and Control of Non-Verbal Signs of Speech Anxiety & Quantitative & Literature Review
\end{tabular}

\section{Results and Future Implications}

Archival Activities. For over six years faculty had been participating in poster activities. These posters were concepts of best practices for classroom engagement that never evolved into formal research or scholarship activities. This action research drew on those archival activities to create the Community of Scholars Action Research Project. In fall 2015, twenty-three practitioner faculty members attended a training on how to develop a research prospectus. Several of those prospectus proposals or poster became formal research projects for the Community of Scholars initiative. In winter 2016 unofficial interviews with practitioner faculty members identified skill gaps that interfered with pursuing research and scholarship. Many of the faculty members expressed a desire to formally document and publish their classroom best practices. These skill gap conversations, and the requirements for faculty scholarship, laid the foundation for this research project and the formation of the Community of Scholars.

Discussion. The Community of Scholars Action Research study officially started in November 2016 with a training event on Action Research. Twenty-three practitioner faculty members attended the launch event and submitted consent to participate agreements. Using a research project to explore a new faculty engagement and development initiative was an experiential learning experience for all involved. We discovered that challenges, processes, and 
opportunities to form a Community of Scholars among practitioner faculty required a scholarly leader approach. A scholarly leader approach allowed the leaders to draw on various leadership behaviors.

The data collection points provide qualitative feedback to gain an understanding on how faculty were progressing with research and scholarships. The researchers discovered how to encourage intellectual inquiry by using a community membership approach and by asking faculty what would be of value to them as a Community of Scholars. Researchers discovered that the formation of a COS did have an impact on faculty engagement in research when skill gaps could be narrowed. They found that what worked well was to have a planned agenda of research or scholarship events that provided training and opportunities to discuss research projects or scholarship ideas. As the titles of COS research projects were reviewed, they found that most of these faculty research projects were about students, student behaviors, or learning.

Another key observation by the leaders was reflective of the turbulence of our times. Specifically, some faculty members were initially hesitant to share their research ideas. They expressed fears that other people or researchers would benefit from their intellectual property; that was their underlying hesitation to engage with community members. This fear was an interesting finding because it was reflective of behaviors seen with students in learning teams taught by these same faculty members. This finding communicated to the researchers (the campus leaders) that faculty development should include training to help faculty members voice and overcome their personal uncertainties and social conflicts. If they are not equipped themselves how can they help students to voice and overcome uncertainties and social conflicts? After coaching by the researchers, the faculty members became less hesitant to share with each other. Fear of sharing intellectual accomplishments could become a separate research project.

One primary concern, which became evident after the initial launch of the action research, was how to create ongoing engagement between scholarship events. During the initial stage of the project, the leaders created a weekly Community of Scholars weekly update email. This communication was designed to keep the community informed and updated. In addition, the researchers created a Next Step Challenge to encourage community members to move research or scholarship projects to the next step, before specific engagement events. The goal for the challenge was to ease concerns and allow everyone to start where they were. As leaders, it was critical to allow practitioners to advance into research or scholarship at their own pace and to be considerate of their other job, family, or business responsibilities. Future studies on stakeholder engagement could explore motivators for engagement with a community or project.

Two community members were enlisted to lead the community and to help sustain engagement. The Community of Scholars Liaison (a title created by a faculty member) became the research overseer for the community. He offered to help COS members to design a survey or questionnaire for their research. The other Community of Scholars Liaison serves as the communication liaison. She took an active role posting information on the campus research site.

Many of the participants wanted to pursue individual research projects but did not know how to get started. The Knowledge without Boundaries Academy was a great help for training and support. Although the collaborations teams were created as a vehicle for ongoing engagement, 
support, and peer to peer learning, there was still a need for the leaders to promote engagement among COS members. A future study could be to evaluate stakeholder's response to opportunities for collaborations.

The action research project pushed leaders and COS members outside of their comfort zones. Everyone was discovering and learning new things about research, scholarship, and being a Community of Scholars. As the Community of Scholars continues engagement, the expected outcome is for participants and leaders to continuously discover and learn while enhancing professional academic profiles. The expectation is that as community members become more comfortable with research and scholarship, they will continue to expand into industry collaborations for research. Conceptually, this Community of Scholars initiative has potential to inspire a new model for faculty or stakeholder development that goes beyond teaching and classroom management. A final conceptual objective of this research is to consolidate the individual research projects generated by the Community of Scholars in a first- year publication.

This type of research activity has potential to impact student outcomes, which aligns with the purpose of the study. When practitioner faculty engage in intellectual inquiry that could benefit student outcomes we align with HLC requirements. Recommendations for future research are broad and far reaching. This study, or the scholarly leader approach, could be duplicated or adapted in any environment that requires initiating stakeholder engagement or professional development.

Early Wins. In June 2016, three faculty members presented their research proposals at an academic conference, these proposals became formal research projects as the Community of Scholars evolved. This exposure provided those faculty members with opportunity to enhance their professional academic identities. One faculty member received a research grant and presented her research at the Total Quality Review conference in January 2017. The researchers presented the conception of the Community of Scholars at the Association of Leadership Educators Conference in July 2016 and at a Knowledge without Boundaries conference in August 2016. The researchers submitted the project for peer review acceptance for several conferences. They presented at the Total Quality Review conference in January 2017, the International Leadership Association Women's Conference in June 2017, a Knowledge without Boundaries conference in July 2017, and will be presenting at the International Leadership Conference in Brussels, October 2017.

Future Implications. In addition to the conference presentation we (researchers) also received a request from a representative of Cardinal Stritch University to share the project plan and to collaborate on running a similar program at that university. These archival and early wins provide implications of how this research study contributes new knowledge concerning leadership and faculty development. While this research study drew from servant, situational, and transformational theoretical positions on leadership, a potential new leadership framework or profile evolved. We termed this framework "scholarly leadership". This term evolved as we realized that we had approached the workplace problem seeking to learn what we did not know as a scholar and a leader. 
A scholar is a generally understood as learned person who has done advanced study in a special field while a leader is someone who leads. We did not assume to know how to engage practitioner faculty in research or scholarship activities. This is because we had not been faced with this as a prior leadership challenge. Recognizing our personal knowledge gaps, we began with the goal to study how to create a culture of intellectual inquiry among existing practitioner faculty and ourselves. The action research approach gave us a platform for learning, engagement and professional development that we all benefited from.

The implications are that workplace or organizational problems could be tackled by using a research or scholarly leadership framework when stakeholder engagement is the goal. When the leader approaches a problem with intellectual inquiry and intentionality to learn, it allows the leader to adapt a variety of leadership personas based on individual stakeholder needs. The leader is then in a position of learning while leading, thus opening doors for ideas and input that has foundational research and scholarship implications. The scholarly leadership framework has potential for use in any environment because it level sets the leader's role and activates the stakeholder's engagement.

\section{References}

Bartunek, J. M. (2014) Academic-practitioner relationships: What NTL started and what management scholarship keeps developing. The Journal of Applied Behavioral Science 2014, Vol. 50(4) 401-422. DOI: 10.1177/0021886314548671

Bartunek, J. M. \& Rynes, S. L. (2014). Academics and practitioners are alike and unlike: The paradoxes of academic-practitioner relationships. Journal of Management Vol. 40 No. 5, 1181-1201. DOI: 10.1177/0149206314529160

Bass, B. M. (1985). Leadership and performance beyond expectations. New York: Free Press

Blanchard, K.H. (1985). SLII: a situational approach to managing people. Escondido, CA: Blanchard Training and Development

Boyer, E. (1990). Scholarship Reconsidered: Priorities of the Professoriate. San Francisco: Jossey-Bass. The Carnegie Foundation for the Advancement of Teaching.

Burns, J.M. (1978). Leadership. New York: Harper \& Row

Cardwell, J., Ellis, B., \& Phelps, Y. (2016). Prospecting for Leaders in Education Research by Forming a Community of Scholars. Association of Leadership Educators 26th Annual Conference Proceedings. http://www.leadershipeducators.org/resources/Documents/Annual\%20Conference\%20Pr oceedings\%202016.pdf 
Elliott, J. (2010). Building social capital for educational action research: the contribution of Bridget Somekh. Educational Action Research (18) 1. Pp. 19-28. DOI: 10.1080/09650790903484509

Greenleaf, R.K. (1970). The servant as leader. Newton Centre, MA: Robert Greenleaf Center

Greenleaf, R.K. (1977). Servant leadership: A journey into the nature of legitimate power and greatness. New York: Paulist

Hersey, P., \& Blanchard, K.H. (1969). Life-cycle theory of leadership. Training and Development Journal, 23, 26-34.

Higher Learning Commission (2013) Criteria for Accreditation. Retrieved from https://www.hlcommission.org/Criteria-Eligibility-and-Candidacy/criteria-and-corecomponents.html

Johnson, L., Adams Becker, S., Estrada, V., \& Freeman, A. (2015). NMC Horizon Report: 2015 higher education edition. Austin, TX: New Media Consortium. Retrieved from http://cdn.nmc.org/media/2015-nmc-horizon-report-HE-EN.pdf

Northouse, P.G. (2007). Leadership Theory and Practice 4th Ed. Sage Publications: Thousand Oaks, CA

Perruci, G. (2011). Millennials and globalization: The cross-cultural challenge of intragenerational leadership. Journal of Leadership Studies, 5(3), 82-87

Raina, K, \& Khatri, P.(2015). Faculty engagement in higher education: prospects and areas of research. On the Horizon, Vol. 23 Is 4 pp. 285 - 308. DOI.org/10.1108/OTH-032015-0011

Ravitch, S.M. \& Riggan, M. (2012). How conceptual frameworks guide research. Thousand Oaks, CA: Sage

Reybold, L.E. (2008) Practitioner-faculty dialectic: Balancing professional identities in adult education. Journal of Adult Development 15:140-147. DOI 10.1007/s10804-008-9045-8 Springer Science Business Media, LLC

Schwarz, G. \& Stensaker, I. (2014). Time to take off the theoretical straightjacket and reintroduce phenomenon-driven research. The Journal of Applied Behavioral Science Vol. 50(4) 478-501. DOI: 10.1177/0021886314549919

Yin, R.K (1994). Discovering the future of the case study. Method in evaluation research. The American Journal of Evaluation (15) 3, 283-290. doi:10.1177/1098214094015003 


\section{Author Biographies}

Dr. Janice (Jan) Lewis Cardwell is the Vice President/Director of the University of Phoenix Detroit. Her research interests include educational leadership, and the influence that faculty have on student motivation and learning. She is also a dissertation chair, and a research fellow for the University and she lives in West Bloomfield, Michigan. janice.cardwell@ comcast.net

Dr. Bonnie Ellis is the Director of Academic Affairs for the University of Phoenix Detroit. Her research interests are communication, public speaking, and leadership development. She developed the Awareness and Control Method to overcome speech anxiety. She is also an associate faulty member and she lives in Romeo, Michigan. bonniemellis@gmail.com

Dr. Yvonne Phelps is the Vice President of Academic Affairs for Campus Services at the University of Phoenix. Her research interests include learning assessment, corporate ethics, generational differences, and organizational downsizing. She is also an associate faculty member and dissertation chair for the University. Yvonne lives in Cave Creek, Arizona. 